\title{
Péptidos antimicrobianos, una alternativa prometedora para el tratamiento de enfermedades infecciosas
}

\author{
Kevin Samael Olascoaga-Del Angel, Grecia Sánchez-Evangelista, Israel Carmona-Navarrete, \\ María del Carmen Galicia-Sánchez, Angélica Gómez-Luna, Susan Janneth Islas-Arrollo \\ y Jorge Ismael Castañeda-Sánchez \\ Universidad Autónoma Metropolitana Unidad Xochimilco, Ciudad de México, México
}

\begin{abstract}
Resumen
Los microorganismos causantes de enfermedades en humanos evolucionan constantemente, lo que representa un reto en la búsqueda de tratamientos efectivos contra estos patógenos. Aun cuando en la actualidad se cuenta con diversas alternativas farmacológicas, estas en ocasiones resultan ineficientes para el control de las enfermedades infecciosas, sobre todo porque los patógenos han generado múltiples mecanismos de resistencia. Los péptidos antimicrobianos se han descrito en muchas especies de organismos: hongos, plantas, insectos y humanos; en la actualidad se presentan como una solución terapéutica que puede ser efectiva. La ventaja de estos péptidos naturales es que llevan evolucionando casi la misma cantidad de tiempo que las especies que producen y su efecto en el control de los microorganismos es muy notable; algunas de estas moléculas son aisladas de organismos vivos y otras se comienzan a producir por métodos sintéticos, lo que permite tener acceso a un sinfín de posibles péptidos con actividades terapéuticas diversas.
\end{abstract}

PALABRAS CLAVE: Péptidos antimicrobianos. Enfermedades infecciosas. Resistencia a fármacos.

\begin{abstract}
Microorganisms that cause diseases in humans are constantly evolving, which represents a challenge in the search for effective treatments against them. Even when currently there are several pharmacological alternatives available, sometimes they are inefficient for the control of infectious diseases, especially because pathogens have generated multiple resistance mechanisms against them. Antimicrobial peptides have been described in many species of organisms, from fungi, plants and insects to humans; currently, there are molecules that appear as a solution that can be effective in modern therapeutics. The advantage of these natural peptides lies in that they have been evolving almost the same amount of time than the species that produce them and their effect on the control of microorganisms is highly significant; some of these molecules are isolated from living organisms, others are starting to be produced by synthetic methods, which allows having access to an endless number of peptides with diverse therapeutic activities.
\end{abstract}

KEY WORDS: Antimicrobial peptides. Infectious diseases. Drug resistance.

\section{Péptidos antimicrobianos de humanos}

Los péptidos antimicrobianos (PAM) son moléculas relativamente pequeñas que contienen entre 12 y 60 aminoácidos, forman parte de la respuesta de defensa de diversas especies de organismos y participan mediando la respuesta primaria hacia varios patógenos como bacterias, parásitos, infecciones víricas y fúngicas. En mamíferos son sintetizados en la piel, mucosas o sitios propensos a las infecciones. ${ }^{1}$

El primer PAM de origen animal fue aislado de leucocitos de conejo en $1956 .{ }^{2}$ En la actualidad se han descubierto o sintetizado más de 5000 PAM de origen
Correspondencia:

Jorge Ismael Castañeda-Sánchez

E-mail: jcastanedas@correo.xoc.uam.mx
Fecha de recepción: 05-05-2017

Fecha de aceptación: 25-03-2018

DOI: 10.24875/GMM.18003445
Gac Med Mex. 2018;154:681-688

Disponible en PubMed

www.gacetamedicademexico.com 
natural, tanto de células eucariotas (animales, plantas, hongos, insectos) como procariotas (bacterias). ${ }^{3,4}$

Los PAM en humanos son capaces de activar diversos mecanismos de la respuesta inmunológica como la fagocitosis, liberar prostaglandinas, neutralizar los efectos de los lipopolisacáridos, aumentar la cantidad de células inmunes en sitios de inflamación y reparar heridas mediante la activación de los sistemas de cicatrización. ${ }^{5}$ Estas moléculas generalmente presentan carga positiva y se clasifican en dos grandes grupos: defensinas y catelicidinas. ${ }^{6}$

De acuerdo con su estructura molecular, las defensinas se subdividen en $\alpha$ y $\beta .^{7}$ Son producidas por la mayoría de las células somáticas y por células de la respuesta inmune, se presentan en altas concentraciones en el sitio de inflamación, en procesos infecciosos y algunas se detectan en plasma en concentraciones basales. ${ }^{8}$

Las defensinas $\alpha$ contienen seis residuos de cisteína y tres puentes disulfuro, son producidas por leucocitos y células epiteliales. Existen seis $\alpha$ defensinas descritas en los humanos, las primeras cuatro fueron identificadas en los neutrófilos (HNP 1-4) y las otras dos en las células de Paneth intestinales. ${ }^{9}$

Las defensinas $\beta$ poseen estructuras similares a las del tipo $\alpha$. Existen cuatro tipos de defensinas $\beta$ humanas (hBD 1-4); son producidas por células epiteliales, células del tracto respiratorio y urinario, así como por queratinocitos. ${ }^{8}$

Las catelicidinas son péptidos cortos que contienen un grupo amino-terminal y al otro extremo un grupo carboxilo-terminal, la carga de esta molécula es positiva por lo que es considerada un péptido catiónico. Las catelicidinas presentan acción rápida contra patógenos, son potentes y contienen un amplio espectro de actividad antimicrobiana. La catelicidina con mayor relevancia descrita en los humanos es la LL-37, conformada por una estructura $\alpha$ helicoidal; las células que la producen la secretan en su forma inactiva y su activación se lleva a cabo por proteasas, dejando un péptido de 37 residuos de aminoácidos con dos leucinas seguidas en uno de los extremos. ${ }^{7}$

\section{Mecanismo general de acción}

El mecanismo general por el cual los péptidos ejercen su acción consiste en dañar la membrana celular del patógeno. La interacción del PAM con el microorganismo es mediante fuerzas electrostáticas entre su residuo aminopositivo y la carga negativa de la membrana celular del patógeno. La interacción de los PAM con la célula patógena depende de la composición de la membrana del patógeno, así como de la concentración del péptido antimicrobiano disponible. Si existe afinidad del PAM por la membrana del patógeno se formarán poros intramembranales a través de la bicapa lipídica de la membrana, lo cual provoca su lisis y, por lo tanto, la muerte. ${ }^{10}$

Casi todos los PAM interactúan con los lípidos de la membrana celular, pero otros requieren receptores para ejercer su actividad. ${ }^{11}$ Posiblemente la muerte celular causada por los PAM involucra la interrupción de la síntesis de la membrana seguida de lisis celular. No siempre el mecanismo se centra en la membrana del patógeno; se han descrito interacciones de los PAM con otros blancos como la pared celular, ADN, ARN y moléculas involucradas con la síntesis de las proteínas. ${ }^{12}$

El potencial y aplicaciones de los PAM son casi ilimitados, ya que en la naturaleza se han caracterizado miles de estas moléculas, además, por la vía sintética se pueden obtener millones de posibles péptidos con actividad farmacológica. Conforme los resultados de estudios clínicos, en modelos animales y estudios in vitro, se ha sugerido que los PAM pueden ser moléculas muy prometedoras para el tratamiento de las enfermedades infecciosas. ${ }^{13}$ Aun cuando los PAM de humano son efectivos, la mayoría de las investigaciones se han centrado en la obtención y purificación de moléculas provenientes de insectos, plantas y otros mamíferos.

\section{PAM en el tratamiento de las enfermedades infecciosas}

Los PAM se están usando en el tratamiento de enfermedades causadas por patógenos, algunos se encuentran en fases experimentales y otros ya se comercializan, por ejemplo se emplean PAM contra agentes fúngicos como Candida albicans, Cryptococcus neoformans y Fusarium oxysporum; ${ }^{14}$ se han desarrollado algunos péptidos antivirales de aplicación tópica que combaten la infección por el virus de la inmunodeficiencia humana y el virus del papiloma humano,,$^{15}$ así como PAM que combaten protozoarios y nemátodos ${ }^{16}$ y contra bacterias gramnegativas; ${ }^{17}$ algunos otros son usados por su efecto neuroprotector y antitumoral. ${ }^{18,19}$

\section{PAM antifúngicos}

Los hongos son un extenso grupo de microorganismos presentes en casi cualquier ambiente, forman 
parte de la microbiota humana y animal, algunos tienen la capacidad de ocasionar enfermedades peligrosas para el humano, la mayoría no letales pero sí crónicas. ${ }^{20}$

Las propiedades de los PAM antifúngicos llevan más de 40 años en investigación. Recientemente ha crecido el interés por compuestos antifúngicos debido a los mecanismos de resistencia desarrollados por los patógenos de este tipo. ${ }^{21}$ Aproximadamente 100 péptidos con propiedades antifúngicas se han aislado y se encuentran en diferentes etapas de investigación, la mayoría son de origen natural, aunque el número de péptidos semisintéticos y sintéticos va en aumento. Los PAM antifúngicos por lo general son moléculas lineales y cíclicas, con propiedades anfipáticas o hidrofóbicas, exhiben actividad de lisis, unión y ruptura de la membrana externa. ${ }^{22}$

El mecanismo de acción de los PAM antifúngicos es poco conocido, algunos péptidos se unen con proteínas de la envoltura nuclear de ciertas especies de hongos, produciendo especies reactivas de oxígeno, flujo de salida de iones y ATP; esta serie de eventos da como resultado la muerte celular. Algunos PAM contienen proteínas reguladoras mitocondriales implicadas en el metabolismo de energía de los hongos, lo cual regula positivamente su síntesis y disminuye la síntesis de ATP mitocondrial. ${ }^{23}$ Otro mecanismo es la alteración de la tensión superficial de la membrana, lo que produce la formación de poros y liberación de $\mathrm{K}^{+} \mathrm{y}$ otros iones

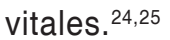

Los PAM antifúngicos con mayor importancia y que, además, están relacionados estructuralmente son las defensinas aisladas de plantas, animales e insectos. ${ }^{26}$

La comercialización de péptidos con actividad antifúngica es relativamente reciente. La Food and Drug Administration de Estados Unidos ha aprobado péptidos antifúngicos que demostraron ser viables en el tratamiento de patógenos comunes en humanos; muchas de estas moléculas se comercializan en forma de aplicación tópica ${ }^{27-35}$ (Tabla 1)

\section{PAM antivirales}

Algunas enfermedades en humanos y animales son ocasionadas por virus como la influenza, el dengue, la hepatitis $\mathrm{C}$, el herpes simple, por citar algunas. Contra ellas, las terapias antivirales son limitadas, incluso, para algunas aún no se ha encontrado la cura; aunado a esto se ha visto incrementada la formación de resistencia de estos virus a los medicamentos, por lo que en la actualidad es un reto la terapia antiviral. Entre las innovaciones para afrontarlo se encuentran los péptidos antivirales (PAV), que prometen ser excelentes opciones. ${ }^{36}$

Los PAV son parte de los péptidos antimicrobianos que pueden actuar directamente 0 a través de la respuesta inmune inhibiendo una o más etapas del ciclo de vida de los virus, ya sea la entrada, replicación, transcripción, etcétera, mostrando un claro efecto antiviral. ${ }^{37}$

En 1985 se reveló uno de los primeros estudios de estos PAV, en el que se demostró la inhibición de la replicación del virus del herpes simple. ${ }^{37}$ Posteriormente otros investigadores lo tomaron como base para continuar trabajando con el desarrollo antiviral.

Algunas ventajas de los fármacos basados en PAV en relación con los convencionales son su bajo peso molecular, su mayor eficiencia, su menor toxicidad y que tienen menos efectos secundarios. Estos PAV se pueden modificar fácilmente con la adición de grupos químicos o aminoácidos para mejorar su actividad y estabilidad. El primer PAV que aprobó los ensayos clínicos fue enfuvirtida (T20), inhibidor de la fusión del VIH que actualmente se vende bajo el nombre de Fuzeon. 38,39

\section{Cecropina y melitina}

La cecropina y la melitina son péptidos antimicrobianos $\alpha$-helice aislados de insectos con actividad antiviral y antimicrobiana (gramnegativos). La familia de las cecropinas incluye sarcotoxinas, hifancina, enboncina y espodopsina.

La melitina es un péptido catiónico de dos $\alpha$-hélices unidas por un segmento flexible y estructura anfipática, tiene 26 residuos de aminoácidos y su acción es inhibir la replicación de los retrovirus murinos, virus del mosaico del tabaco y el virus del herpes simple, así como promover la lisis directa de las membranas virales. A concentraciones bajas también demuestra actividad antiviral para células $T$ infectadas crónicamente con el VIH-1. ${ }^{40,41}$

\section{Aloferones}

Los aloferones son péptidos aislados de la hemolinfa de larvas de mosca Calliphora vicina, son producidos como moléculas de 13 residuos (aloferón 1) y 12 residuos (aloferón 2), el nombre fue dado para demostrar la similitud funcional con la citocina 
Gaceta Médica de México. 2018;154

Tabla 1. Péptidos antifúngicos

\begin{tabular}{|c|c|c|c|c|c|}
\hline Compuesto & Compañía & Estructura & Origen & Uso & $\begin{array}{l}\text { Fase de } \\
\text { evaluación }\end{array}$ \\
\hline $\begin{array}{l}\text { Iseganan. }{ }^{28} \\
\text { (IB-367) }\end{array}$ & $\begin{array}{l}\text { Intrabiotics } \\
\text { Pharmaceuticals }\end{array}$ & $\begin{array}{l}\text { Péptidos con } \\
\text { puentes disulfuro }\end{array}$ & Leucocitos de cerdo & $\begin{array}{l}\text { Mucositis inducida por } \\
\text { terapia anticancerígena }\end{array}$ & Fase III \\
\hline $\begin{array}{l}\text { Omiganan. }{ }^{28} \\
\text { (MBI-226) }\end{array}$ & Microbiologix Biotech & Péptido catiónico & Neutrófilos bovinos & $\begin{array}{l}\text { Reducción de infección por } \\
\text { catéter }\end{array}$ & Fase III \\
\hline Cm-p1. ${ }^{29}$ & $\begin{array}{l}\text { Universidad de la } \\
\text { Habana }\end{array}$ & $\begin{array}{l}\alpha \text {-hélice } \\
\text { hidrofóbico }\end{array}$ & $\begin{array}{l}\text { Cenchritis } \\
\text { muricatus }\end{array}$ & $\begin{array}{l}\text { Inhibidor de actividad } \\
\text { in vitro de varios hongos } \\
\text { filamentosos }\end{array}$ & Fase I \\
\hline Arencina- $1 .{ }^{30}$ & $\begin{array}{l}\text { Adenium } \\
\text { Biotech }\end{array}$ & $\beta$-hélice & $\begin{array}{l}\text { Arenicola } \\
\text { marina }\end{array}$ & Contra Candida spp. & Preclínica \\
\hline ApoEdpL-W. ${ }^{31}$ & & Lipoproteína & Sintético & Contra Candida spp. & Fase II \\
\hline HM-1 killer ${ }^{32}$ & $\begin{array}{l}\text { Universidad Niigata \& } \\
\text { Applied Life Sciences }\end{array}$ & Toxina & $\begin{array}{l}\text { Toxina de Williopsis } \\
\text { mrakii }\end{array}$ & $\begin{array}{l}\text { Contra Candida spp. y } \\
\text { Cryptococcus spp. }\end{array}$ & Fase I \\
\hline PAF-26 33 & $\begin{array}{l}\text { Instituto de Agroquímica } \\
\text { y Tecnología de } \\
\text { Alimentos-CSIC }\end{array}$ & Hexapéptido & Sintético & $\begin{array}{l}\text { Neurospora crassa } \\
\text { Penicillium digitatum } \\
\text { Saccharomyces cerevisiae }\end{array}$ & Fase I \\
\hline $\begin{array}{l}\text { Echinocandin } \\
\mathrm{B}^{34}\end{array}$ & Pharmatech & Lipopéptido & $\begin{array}{l}\text { Fermento de } \\
\text { Zalerionarboicola }\end{array}$ & $\begin{array}{l}\text { Pneumocystis carinii } \\
\text { Aspergillus aculeatus. }\end{array}$ & Fase II \\
\hline Pneumocadin ${ }^{35}$ & Pharmatech & Éter de fosfato & Semisintético & Candida albicans. & Clínica \\
\hline Mulundocandin ${ }^{35}$ & $\begin{array}{l}\text { Aventis Pharma } \\
\text { Deutschland }\end{array}$ & Lipopéptido & Aspergillus syndowi & $\begin{array}{l}\text { Candida albicans } \\
\text { Aspergillus niger }\end{array}$ & Fase II \\
\hline
\end{tabular}

denominada interferón. Su actividad fue comprobada con un péptido sintético en un modelo de ratones con infección letal pulmonar por virus de la gripe humana A y B; al administrar aloferón se previno la mortalidad de la mayoría de los animales infectados por el virus de la influenza tipo $\mathrm{A}$, además estimuló la resistencia a la infección por virus de la influenza B. Los resultados fueron casi equivalentes a los observados con la administración de ribavirina, por lo que se demostró que el aloferón tiene actividad antiviral. ${ }^{42}$

\section{Péptido N-miristoilado}

Es un compuesto antiviral con bajo peso molecular de 916 kDa extraído de la hemolinfa de larvas de oruga del tabaco Heliothis viresces, tiene seis aminoácidos, la porción N-terminal de este péptido contiene el ácido graso miristoil mientras que el C-terminal, histidina con dos grupos metilo; lo anterior le da la carga positiva permanente. La acción antiviral de este compuesto corresponde a la inhibición de la unión de los virus al lado citoplasmático de la membrana del hospedero, lo que evita el ensamblaje de las partículas virales. Gracias a su pequeño peso molecular y naturaleza no polar puede mejorar su capacidad de atravesar la membrana plasmática desde donde puede inactivar a virus como VIH-1 y HSV-1. ${ }^{42}$

\section{Mecanismos de acción de los PAV}

Los péptidos como el aloferón estimulan las células natural killer (NK) y la producción de interferones tipo 1, que colaboran conjuntamente activando la citotoxicidad de las células NK, las cuales participan activamente en el control de las infecciones por virus. ${ }^{43}$

Otro mecanismo de acción de los péptidos es la influencia en los pasos intracelulares de infección viral, la interacción con el ADN y el ARN mensajero viral. Ejemplos de esto son la melitina y la cecropina $A$, que inhiben la producción de células asociadas con VIH-1 por la supresión de la expresión génica. Cecropina A también inhibe la multiplicación del virus Sendai, por reducción de la síntesis de proteínas virales sin afectar la síntesis de proteínas de la célula hospedera. ${ }^{40}$

Al ser una proteína de membrana, la melitina es capaz de interferir con vías celulares de transducción de señales como la activación de fosfolipasa A2, la disminución de las actividades de la 
carmodulina y la proteína cinasa C; es así como puede cambiar el equilibrio y la actividad estimuladora o inhibidora de transcripción en células infectadas con VIH-1. También puede estar implicada en la regulación postranscripcional de la expresión génica del virus de la inmunodeficiencia humana, influir en la regulación de los ARN mensajeros grandes e intermedios; estudios preliminares revelan que también inhibe la replicación de retrovirus como el que causa la leucemia murina, así como el virus de inmunodeficiencia felina. ${ }^{42}$

Otro ejemplo de PAV es el péptido N-miristoilado, que actúa en el control viral del VIH; su mecanismo probable es la inhibición del ensamblaje o gemación del virus en las células hospederas. ${ }^{44}$

Los péptidos penetradores de células son moléculas que aumentan la captación celular y el tráfico hacia el citoplasma de péptidos que pudieran tener efectos antivirales; básicamente se insertan en las membranas permitiendo el paso de las moléculas realmente efectoras. ${ }^{45,46}$

\section{PAM antibacterianos}

Los PAM antibacterianos se han comenzado a utilizar como una alternativa al uso de antibióticos, que en la actualidad no son suficientes y algunos ya no son eficientes en el control bacteriano. La mayoría de los patógenos bacterianos tienen mecanismos de resistencia a los fármacos actuales, lo que les permite sobrevivir e incluso diseminarse en sus hospederos. La utilización de los PAM podría ser una buena alternativa, sobre todo los que provienen de origen sintético y que ya se encuentran en fases clínicas de estudio ${ }^{47-50}$ (Tabla 2) o los que son aislados directamente de organismos; la mayoría todavía están en fase de experimentación de laboratorio ${ }^{51-54}$ (Tabla 3).

Son múltiples los mecanismos que utilizan los PAM para el control de las bacterias, depende de cada especie; generalmente actúan en la permeabilización de la membrana, alteración del metabolismo e interrupción de las funciones del ADN y proteínas. ${ }^{55}$

\section{PAM antiparasitarios}

Los protozoarios son células eucariotas simples (organismos cuyas células tienen membrana nuclear) con características del reino animal, ya que son móviles y heterótrofos, muchas de estas especies son cosmopolitas mientras que otras son de distribución limitada. ${ }^{56}$
Las infecciones parasitarias en humanos están en aumento debido a la aparición de cepas resistentes a los compuestos antiparasitarios, de tal manera que se ha realizado la búsqueda y desarrollo de nuevos compuestos, centrándose en la extracción y purificación de principios activos de procedencia natural o sintética. Los PAM pudieran ser usados en el control de estas infecciones. ${ }^{57}$

Se ha estudiado la piel de los anfibios, en los que se han descrito alrededor de 400 péptidos con potencial terapéutico, la mayoría se sintetiza en las glándulas granulares que se localizan en la piel, constituyendo un papel importante en la inmunidad innata de estas especies. Estos péptidos están involucrados en la defensa de la piel desnuda contra bacterias patógenas y hongos, además participan en la reparación de las heridas. ${ }^{58,59} \mathrm{Se}$ agrupan en tres familias:

- Péptidos lineales anfipáticos helicoidales (magaininas y dermaseptinas). ${ }^{60}$

- Péptidos que contienen dos residuos de cisteína sobre el grupo carboxilo terminal (brevinas, gaegurinas, esculentinas, ranateurinas y ranalexina). ${ }^{61-63}$

- Las temporinas. ${ }^{64,65}$

Las dermaseptinas forman parte de una familia de ocho péptidos relacionados con la piel de una rana de Sudamérica (Phyllomedusa sauvagei). Son péptidos lineales, de 28 a 34 aminoácidos, con estructura de $\alpha$-hélice y son anfipáticos en disolventes apolares. ${ }^{66}$ Son altamente eficaces contra protozoarios como Leishmania mexicana y Plasmodium falciparum. ${ }^{67,68}$

Las magaininas son moléculas aisladas de las secreciones de la piel de la rana Xenopus laevis, ${ }^{69}$ diversos estudios han reportado que tienen un espectro con actividad antimicrobiana bastante amplia contra bacterias, hongos y parasitos, además de participar en la activación de mecanismos que reducen la inflamación. ${ }^{70}$

\section{Otros PAM. Propiedades antibacterianas del veneno de escorpión}

Aunque la existencia de algunos péptidos antibacterianos en venenos de escorpión sugiere que la glándula de veneno podría estar protegida por estas moléculas efectoras, la actividad antibacteriana del veneno en sí no ha sido evaluada extensamente. ${ }^{71}$

Algunos péptidos antibacterianos han sido aislados mediante cromatografía de intercambio iónico de los venenos de los escorpiones Hadruroides mauryi y Centruroides margaritatus (Tabla 4); aunque pueden 
Gaceta Médica de México. 2018;154

Tabla 2. Péptidos con efecto antibacteriano

\begin{tabular}{|c|c|c|c|c|c|}
\hline Compuesto & Compañía & Estructura & Origen & Microorganismo inhibido & $\begin{array}{l}\text { Fase de } \\
\text { evaluación }\end{array}$ \\
\hline $\mathrm{BmKn} 2^{48}$ & $\begin{array}{l}\text { Universidad } \\
\text { Thammasat }\end{array}$ & $\begin{array}{l}\text { Péptido básico, } \\
\text { alfa-helicoidal sin puente } \\
\text { disulfuro }\end{array}$ & Alacrán & Miseria gonorrhoeae & Fase II \\
\hline GL13K ${ }^{49}$ & $\begin{array}{l}\text { Universidad de } \\
\text { Minnesota }\end{array}$ & $\begin{array}{l}\text { Péptido antimicrobiano de } \\
13 \text { aminoácidos }\end{array}$ & $\begin{array}{l}\text { Glándulas salivales } \\
\text { de humano }\end{array}$ & $\begin{array}{l}\text { Reducción de biopelículas } \\
\text { de Pseudomonas aeruginosa }\end{array}$ & Clínica \\
\hline Alysterin-150 & Bio-X & $\beta$-hélice & Sintético & Escherichia coli & Clínica \\
\hline A3APO 50 & $\begin{array}{l}\text { Universidad de } \\
\text { Minnesota }\end{array}$ & Lipopéptido & Sintético & $\begin{array}{l}\text { Escherichia coli } \\
\text { Salmonella spp. }\end{array}$ & Preclínica \\
\hline XMP. $629^{13}$ & Xoma technology & Péptido de 9 aminoácidos & Sintético & Propionibacterium acnes & Fase I \\
\hline CEME $^{51}$ & $\begin{array}{l}\text { Universidad British } \\
\text { Columbia }\end{array}$ & $\alpha$-hélice & Sintético & $\begin{array}{l}\text { Staphylococcus aureus } \\
\text { Staphylococcus epidermidis } \\
\text { Streptococcus pneumoniae }\end{array}$ & Clínica \\
\hline CEMA $^{51}$ & $\begin{array}{l}\text { Universidad } \\
\text { British Columbia }\end{array}$ & $\begin{array}{l}\text { CEME modificado con } \\
\text { dos péptidos extra }\end{array}$ & $\begin{array}{l}\text { Producido } \\
\text { por plantas } \\
\text { transgénicas }\end{array}$ & $\begin{array}{l}\text { Porphyromonas gingivalis } \\
\text { Streptococcus mutans }\end{array}$ & Clínica \\
\hline MBI 594AN 13 & Microbiologix Biotech & Lipopéptido & Sintético & Propionibacterium acnes & Fase II \\
\hline Neuprex ${ }^{13}$ & Xoma technology & $\beta$-hélice & Sintético & Neisseria meningitidis & Fase III \\
\hline
\end{tabular}

Tabla 3. Péptidos aislados de humanos con efecto antibacteriano

\begin{tabular}{|c|c|c|c|c|}
\hline $\begin{array}{l}\text { Péptido } \\
\text { antimicrobiano }\end{array}$ & Estructura & Producción/síntesis & Acción & $\begin{array}{l}\text { Microorganismos } \\
\text { inhibidos }\end{array}$ \\
\hline Defensinas hBD3 ${ }^{52,53}$ & $\begin{array}{l}\text { Péptidos lineales con } \\
\text { estructura alfa helicoidal }\end{array}$ & Estímulos inflamatorios & $\begin{array}{l}\text { Activación de la respuesta } \\
\text { innata }\end{array}$ & $\begin{array}{l}\text { Staphylococcus aureus } \\
\text { Mycobacterium tuberculosis }\end{array}$ \\
\hline Lactoferrinas $s^{5,55}$ & $\begin{array}{l}\text { Cadena polipeptídica simple, } \\
\text { plegada en dos lóbulos } \\
\text { globulares simétricos }\end{array}$ & $\begin{array}{l}\text { Producidas por las } \\
\text { células epiteliales de las } \\
\text { mucosas }\end{array}$ & $\begin{array}{l}\text { Funcionan como } \\
\text { bacteriostáticos y } \\
\text { bactericidas }\end{array}$ & $\begin{array}{l}\text { Listeria monocytogenes } \\
\text { Streptococcus mutans } \\
\text { Staphylococcus aureus } \\
\text { Bacillus stearothermophilus }\end{array}$ \\
\hline
\end{tabular}

ser usados en el control de bacterias, su actividad tiene que ser evaluada específicamente. ${ }^{72}$

\section{Conclusión}

Debido a la resistencia a fármacos que presentan los microorganismos, es necesario implementar nuevos mecanismos de tratamiento utilizando como modelo sustancias de la naturaleza que sean capaces de actuar directamente en el control de los patógenos o que indirectamente activen al sistema inmune del hospedador. Los PAM pueden ser una excelente opción para el tratamiento de enfermedades infecciosas, ya que existe una gran diversidad de estas moléculas y sus usos no se limitan a infecciones causadas por microorganismos comunes (bacterias, virus, hongos y parásitos). También se ha puesto atención en los que puedan ser una opción contra el cáncer.
Los péptidos antimicrobianos para uso terapéutico se pueden obtener mediante síntesis químicas 0 aislados directamente de alguna fuente natural, por lo que su número puede ser bastante amplio. Los PAM por sí solos muestran un amplio espectro, lo que falta por explorar es la posibilidad de combinarlos en el tratamiento de infecciones, con fármacos que se encuentran disponibles comercialmente y que se usan convencionalmente, con el fin de evaluar si la terapia combinada pueda potenciar su efecto.

El uso de estas moléculas cada vez es más frecuente y exitoso, y a pesar de que ciertos péptidos aún se encuentran en etapas clínicas tempranas, su uso a mediano plazo puede ser una opción prometedora, sobre todo si consideramos la resistencia a fármacos que han desarrollado muchos patógenos que generan enfermedades en los humanos. 
Tabla 4. Péptidos derivados de Hadruroides mauryi y Centruroides margaritatus

\begin{tabular}{|c|c|c|}
\hline Organismo & $\begin{array}{l}\text { Fracciones } \\
\text { activas }\end{array}$ & $\begin{array}{l}\text { Microorganismos } \\
\text { inhibidos }\end{array}$ \\
\hline \multirow[t]{2}{*}{$\begin{array}{l}\text { Hadruroides } \\
\text { maury }^{72}\end{array}$} & IV & $\begin{array}{l}\text { Escherichia coli } \\
\text { Pseudomonas aeruginosa } \\
\text { Bacillus cereus }\end{array}$ \\
\hline & $\mathrm{VI}$ & Bacillus cereus \\
\hline \multirow{3}{*}{$\begin{array}{l}\text { Centruroides } \\
\text { margaritatus }^{72}\end{array}$} & ॥ & Staphylococcus aureus \\
\hline & III, IV, V y VI & $\begin{array}{l}\text { Staphylococcus aureus } \\
\text { Pseudomonas aeruginosa } \\
\text { Bacillus cereus }\end{array}$ \\
\hline & VII & Pseudomonas aeruginosa \\
\hline
\end{tabular}

\section{Agradecimientos}

Los autores agradecen a la Universidad Autónoma Metropolitana Unidad Xochimilco por el apoyo recibido. El trabajo que se presenta forma parte del proyecto CB-2015-1-258735.

\section{Bibliografía}

1. Jenssen $H$, Hamill $P$, Hancock RE. Peptide antimicrobial agents. Clin Microbiol Rev. 2006;19:491-511.

2. Hirsch JG. Phagocytin: a bactericidal substance from polymorphonuclear leucocytes. J Exp Med. 1956:103:589-611.

3. Conlon J, Sonnevend A. Antimicrobial peptides in frog skin secretions. Methods Mol Biol. 2010;618:3-14.

4. Radek K, Gallo, R. Antimicrobial peptides: natural effectors of the innate immune system. Semin Immunopathol. 2007;29:27-43.

5. Tonarelli G, Simonetta A. Péptidos antimicrobianos de organismos procariotas y eucariotas como agentes terapéuticos y conservantes de alimentos. FABICI. 2013;17:137-177.

6. Rocha-Ferreira E, Hristova M. Antimicrobial peptides and complement in neonatal hypoxia-ischemia induced brain damage. Front Immunol. 2015;12:6:56.

7. Braff MH, Bardan A, Nizet V, Gallo RL. Cutaneous defense mechanisms by antimicrobial peptides. J Invest Dermatol. 2005;125:9-13.

8. Oppenheim J, Biragyn A, Kwak L, Yang D. Roles of antimicrobial peptides such as defensins in innate and adaptive immunity. Ann Rheum Dis. 2003;62:ii17-ii21.

9. Mastroianni JR, Lu W, Selsted ME, Ouellette AJ. Differential susceptibility of bacteria to mouse Paneth cell $\alpha$-defensins under anaerobic conditions. Antibiotics (Basel). 2014;3:493-508.

10. Guilhelmelli F, Viela N, Albuquerque P, Derengowski L, Silva-Pereira I, Kyaw CM. Antibiotic development challenges: the various mechanisms of action of antimicrobial peptides and of bacterial resistance. Front $\mathrm{Mi}-$ crobiol. 2013;4:353

11. Epand RM, Vogel HJ. Diversity of antimicrobial peptides and their mechanisms of action. Biochim Biophys Acta. 1999;1462:11-28.

12. Yeaman MR, Yount NY. Mechanisms of antimicrobial peptide action and resistance. Pharmacol Rev. 2003;55:27-55.

13. Gordon YJ, Romanowski EG. A review of antimicrobial peptides and their therapeutic potential as anti-Infective drugs. Curr Eye Res. 2005;30:505-515

14. De Lucca AJ, Walsh TJ. Antifungal peptides: novel therapeutic compounds against emerging pathogens. Antimicrob Agents Chemother 1999:43:1-11.

15. Buckheit RW, Watson KM, Morrow KM, Ham AS. Development of topical microbicides to prevent the sexual transmission of HIV. Antiviral Res. 2010:85:142-158.

16. Rivas L, Luque-Ortega JR, Andreu D. Amphibian antimicrobial peptides and protozoa: lessons from parasites. Biochim Biophys Acta 2009;1788:1570-1581.

17. Volzing K, Borrero J, Sadowsky MJ, Kaznessis YN. Antimicrobial peptides targeting Gram-negative pathogens, produced and delivered by lactic acid bacteria. ACS Synth Biol. 2013;2:643-650.
18. Hoskin DW, Ramamoorthy A. Studies on anticancer activities of antimicrobial peptides. Biochim Biophys Acta. 2008;1778:357-375.

19. Kim DH, Lee IH, Nam ST, Hong J, Zhang P, Hwang JS, et al. Neurotropic and neuroprotective activities of the earthworm peptide lumbricusin. Biochem Biophys Res Commun. 2014;448:292-297.

20. Enoch D, Ludlam HA, Brown NM. Invasive fungal infections: a review of epidemiology and management options. J Med Microbiol. 2006;55:809-818.

21. De Luca AJ, Walsh TJ. Antifungal peptides: origin, activity, and therapeutic potential. Rev Iberoam Micol. 2000;17:116-120.

22. Shai $Y$. Molecular recognition between membrane-spanning polypeptides. Trends Biochem Sci. 1995;20:460-464.

23. Rautenbach M, Troskie AM, Vosloo JA. Antifungal peptides: To be or not to be membrane active. Biochimie. 2016;130:132-145.

24. De Lucca AJ, Walsh TJ. Antifungal peptides: novel therapeutic compounds against emerging pathogens. Antimicrob Agents Chemother. 1999;43:1-11.

25. Swidergall M, Ernst JF. Interplay between Candida albicans and the antimicrobial peptide armory. Eukaryot Cell. 2014;13:950-957

26. Taylor K, Barran PE, Dorin JR. Structure-activity relationships in beta-defensin peptides. Biopolymers. 2008:90:1-7.

27. Duncan VMS, O'Neil DA. Commercialization of antifungal peptides. Fungal Biol Rev. 2013;26:156-165.

28. Kang HK, Kim C, Seo $\mathrm{CH}$, Park $\mathrm{Y}$. The therapeutic applications of antimicrobial peptides (AMPs): a patent review. J Microbiol. 2017;55:1-12.

29. López-Abarrategui C, Alba A, Silva ON, Reyes-Acosta O, Vasconcelos IM, Oliveira JT, et al. Functional characterization of a synthetic hydrophilic antifungal peptide derived from the marine snail Cenchritis muricatus. Biochimie. 2012;94:968-974

30. Lee JU, Kang DI, Zhu WL, Shin SY, Hahm KS, Kim Y. Solution structures and biological functions of the antimicrobial peptide, arenicin-1, and its linear derivative. Biopolymers. 2007;88:208-216.

31. Rossignol T, Kelly B, Dobson C, D'Enfert C. Endocytosis-mediated vacuolar accumulation of the human ApoE apolipoprotein-derived ApoEdpL-W antimicrobial peptide contributes to its antifungal activity in Candida albicans. Antimicrob Agents Chemother. 2011;55:4670-4681.

32. Kabir ME, Krishnaswamy S, Miyamoto M, Furuichi Y, Komiyama T. An altered camelid-like single domain anti-idiotypic antibody fragment of HM-1 killer toxin: acts as an effective antifungal agent. Appl Microbiol Biotechnol. 2011;90:553-564.

33. López-García B, Pérez-Payá E, Marcos JF Identification of novel hexapeptides bioactive against phytopathogenic fungi through screening of a synthetic peptide combinatorial library. Appl Environ Microbiol. 2002; 68:2453-2460.

34. De Lucca AJ. Antifungal peptides: potential candidates for the treatment of fungal infections. Expert Opin Investig Drugs. 2000;9:273-299.

35. Hawser S, Borgonovi M, Markus A, Isert D. Mulundocandin, an echinocandin-like lipopeptide antifungal agent: biological activities in vitro. J Antibiot (Tokyo). 1999;52:305-310.

36. Qureshi A, Thakur N, Tandon H, Kumar M. AVPdb: a database of experimentally validated antiviral peptides targeting medically important viruses. Nucleic Acids Res. 2014:42:D1147-D1153.

37. Imanishi J, Oku T, Cho Y, Inagawa S, Tanaka A, Kuwayama W. Inhibition of virus multiplication by immunoactive peptides. C R Seances Soc Biol Fil. 1985:179:414-419.

38. Zasloff, M. Antimicrobial peptides of multicellular organisms. Nature. 2002;415:389-395

39. Fung $H B$, Guo $Y$. Enfuvirtide: a fusion inhibitor for the treatment of HIV infection. Clin Ther. 2004:26:352-378.

40. Wachinger M, Kleinschmidt A, Winder D, Von-Pechmann N, Ludvigsen A, Neumann M, et al. Antimicrobial peptides melittin and cecropin inhibit replication of human immunodeficiency virus 1 by suppressing viral gene expression. J Gen Virol. 1998;79:731-740.

41. Albiol-Matanic VC, Castilla V, et al. Antiviral activity of antimicrobial cationic peptides against Junin virus and herpes simplex virus. Int J Antimicrob Agents. 2004;23:382-389.

42. Chernysh S, Kim SI, Bekker G, Pleskach VA, Filatova NA, Anikin VB, et al. Antiviral and antitumor peptides from insects. Proc Natl Acad Sci U S A. 2002:99:12628-12632.

43. Slocinska M, Marciniak P, Rosinski G. Insects antiviral and anticancer peptides: new leads for the future? Protein Pept Lett. 2008;15:578-585.

44. Ourth DD. Antiviral activity against human immunodeficiency virus-1 in vitro by myristoylated-peptide from Heliothis virescens. Biochem Biophys Res Commun. 2004;320:190-196

45. Elliott G, O'Hare P. Intercellular trafficking and protein delivery by a herpesvirus structural protein. Cell. 1997;88:223-233.

46. Delcroix M, Riley LW. Cell-penetrating peptides for antiviral drug development. Pharmaceuticals (Basel). 2010;3:448-470.

47. Arpornsuwan T, Buasakul B, Jaresitthikunchai J, Roytrakul S. Potent and rapid antigonococcal activity of the venom peptide BmKn2 and its derivatives against different Maldi biotype of multidrug-resistant Neisseria gonorrhoeae. Peptides. 2014;53:315-320.

48. Hirt H, Gorr SU. Antimicrobial peptide GL13K is effective in reducing biofilms of Pseudomonas aeruginosa. Antimicrob Agents Chemother. 2013:57:4903-4910. 
49. Volzing K, Borrero J, Sadowsky MJ, Kaznessis YN. Antimicrobial peptides targeting Gram-negative pathogens, produced and delivered by lactic acid bacteria. ACS Synth Biol. 2013;2:643-650.

50. Brogden NK, Brogden KA. Will new generations of modified antimicrobia peptides improve their potential as pharmaceuticals? Int J Antimicrob Agents. 2011;38:217-225

51. Rivas-Santiago B, Sada E, Hernández-Pando R, Tsutsumi V. Péptidos antimicrobianos en inmunidad innata de enfermedades infecciosas. Salud Publica de Mex. 2006;48:62-71.

52. Dong $H, L v Y$, Zhao D, Barrow $P$, Zhou X. Defensins: the case for their use against mycobacterial infections. J Immunol Res. 2016;2016:7515687.

53. Palumbo D, lannaccone M, Porta A, Capparelli R. Experimental antibacterial therapy with puroindolines, lactoferrin and lysozyme in Listeria monocytogenes-infected mice. Microbes Infect. 2010;12:538-545.

54. Rodríguez-Franco DA, Vázquez-Moreno L, Ramos-Clamont Montfort G Actividad antimicrobiana de la lactoferrina: mecanismos y aplicaciones clínicas potenciales. Rev Latinoam Microbiol. 2005;47:102-111.

55. Liou JW, Hung YJ, Yang $\mathrm{CH}$, Chen YC. The antimicrobial activity of gramicidin $\mathrm{A}$ is associated with hydroxyl radical formation. PLoS One. 2015;10:e0117065.

56. Yaeger RG. Protozoa: Structure, classification, growth, and development. En: Baron S, editor. Medical Microbiology. Cuarta edición. EE.UU.: University of Texas Medical Branch at Galveston; 1996.

57. Téllez GA, Castaño JC. Péptidos antimicrobianos. Infection. 2010;14:55-67.

58. Hancock RE. Cationic peptides: effectors in innate immunity and novel antimicrobials. Lancet Infect Dis. 2001:1(3):156-164.

59. Wang Z, Wang G. APD: the antimicrobial peptide database. Nucleic Acids Res. 2004;1:590-592.

60. Rollins-Smith LA, Conlon JM. Antimicrobial peptide defenses against chytridiomycosis, an emerging infectious disease of amphibian populations. Dev Comp Immunol. 2005;29:589-598.

61. Cirioni O, Giacometti A, Ghiselli R, Mocchegiani F, Fineo A, Orlando F et al. Single-dose intraperitoneal magainins improve survival in a gram-negative-pathogen septic shock rat model. Antimicrob Agents Chemother. 2002;46:101-104
62. Clark DP, Durell S, Maloy WL, Zasloff M. Ranalexin. A novel antimicrobial peptide from bullfrog (Rana catesbeiana) skin, structurally related to the bacterial antibiotic, polymyxin. J Biol Chem. 1994;269:10849-10855.

63. Goraya J, Wang Y, Li Z, O'Flaherty M, Knoop FC, Platz JE, et al. Peptides with antimicrobial activity from four different families isolated from the skins of the North American frogs Rana luteiventris, Rana berlandieri and Rana pipiens. Eur J Biochem. 2000;267:894-900.

64. Conlon JM, Kolodziejek J, Nowotny N. Antimicrobial peptides from ranid frogs: taxonomic and phylogenetic markers and a potential source of new therapeutic agents. Biochim Biophys Acta. 2004;1696:1-14.

65. Simmaco M, Mignogna G, Canofeni S, Miele R, Mangoni ML, Barra D. Temporins, antimicrobial peptides from the European red frog Rana temporaria. Eur J Biochem. 1996;242:788-792.

66. Mor A, Nicolas P. Isolation and structure of novel defensive peptides from frog skin. Eur J Biochem. 1994;219:145-154.

67. Mor A, Hani K, Nicolas P. The vertebrate peptide antibiotics dermaseptins have overlapping structural features but targets specific microorganisms. J Biol Chem. 1994;269:31635-31641.

68. Krugliak M, Feder R, Zolotarev VY, Gaidukov L, Dagan A, Ginsburg H, et al. Antimalarial activities of dermaseptin S4 derivatives. Antimicrob Agents Chemother. 2000;44:2442-2451.

69. Zasloff M. Magainins, a class of antimicrobial peptides from Xenopus skin: isolation, characterization of two active forms, and partial cDNA sequence of a precursor. Proc Natl Acad Sci U S A. 1987;84: 5449-5453.

70. Wakamatsu K, Takeda A, Tachi T, Matsuzaki K. Dimer structure of magainin 2 bound to phospholipid vesicles. Biopolymers. 2002;64:314-327.

71. Verdonck F, Bosteels S, Desmet J, Moerman L, Noppe W, Willems J, et al. A novel class of pore-forming peptides in the venom of Parabuthus schlechteri Purcell (scorpions: buthidae). Cimbebasia. 2000; 16:247-260.

72. Escobar E, Flores L, Rivera C. Péptidos antibacterianos de los venenos de Hadruroides mauryi y Centruroides margaritatus. Rev Peru Biol. 2008;15:139-142. 